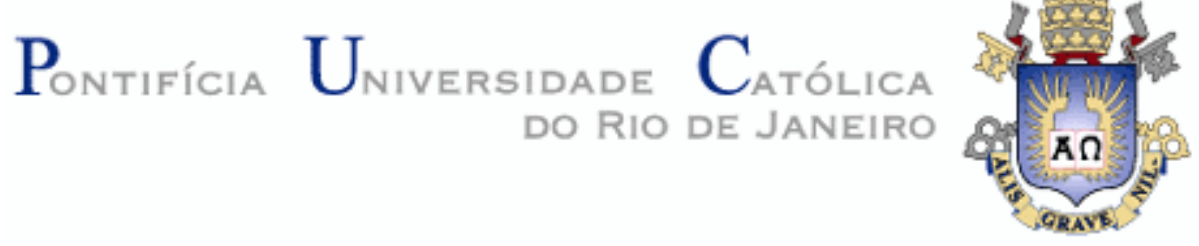

Ana Luiza de Castro Meireles

\title{
Testes Empíricos da Estratégia Dog of Dow nos Mercados Latino Americanos
}

\section{Dissertação de Mestrado}

Dissertação apresentada ao Programa de Pósgraduação em Administração de Empresas da PUCRio como requisito parcial para a obtenção do titulo de Mestre em Administração de Empresas.

Orientador: Prof. André Luiz Carvalhal da Silva 


\section{Pontifícia Universidade $\mathrm{C}_{\text {atólica }}$

Ana Luiza de Castro Meireles

\section{Testes Empíricos da Estratégia Dog of Dow nos Mercados Latino Americanos}

Dissertação apresentada como requisito parcial para obtenção do grau de Mestre pelo Programa de Pósgraduação em Administração de Empresas da PUC-Rio. Aprovada pela Comissão Examinadora abaixo assinada.

Prof. Andre Luiz Carvalhal da Silva Orientador Departamento de Administração - PUC-Rio

Prof. Luiz Felipe Jacques da Motta Departamento de Administração - PUC-Rio

Prof. Ricardo Pereira Câmara Leal

UFRJ

Prof ${ }^{\text {a }}$ Mônica Herz

Vice-Decana de Pós-Graduação do CCS

Rio de Janeiro, 4 de abril de 2012 
Todos os direitos reservados. É proibida a reprodução total ou parcial do trabalho sem a autorização da universidade, da autora e do orientador.

\section{Ana Luiza de Castro Meireles}

Graduou-se em Ciências Econômicas na Universidade Federal do Rio de Janeiro em 2009.

Ficha Catalográfica

\section{Meireles, Ana Luiza de Castro}

Testes empíricos da estratégia Dog of Dow nos mercados latino americanos / Ana Luiza de Castro Meireles ; orientador: André Luiz Carvalhal da Silva. 2012.

38 f. ; $30 \mathrm{~cm}$

Dissertação (mestrado)-Pontifícia Universidade Católica do Rio de Janeiro, Departamento de Administração, 2012.

Inclui bibliografia

1. Administração - Teses. 2. Dog of Dow. 3. Ação de valor. 4. Retorno de dividendo. I. Silva, André Luiz Carvalhal da. II. Pontifícia Universidade Católica do Rio de Janeiro. Departamento de Administração. III. Título. 


\section{Agradecimentos}

Ao meu orientador Professor André Luiz Carvalhal da Silva, pelo apoio ao longo do mestrado, e pela atenção dedicada durante a elaboração desta pesquisa.

Aos Professores Luis Felipe Motta e Ricardo Leal, que participaram da banca desta dissertação, pelos comentários e sugestões que contribuíram para este trabalho.

À minha família, especialmente meus pais, irmão e sobrinhos, e ao meu namorado, pela confiança depositada em mim e apoio incansável durante esses dois anos.

Aos amigos pelo incentivo concedido ao longo da realização desse curso.

Aos amigos da PUC-Rio.

Aos professores e funcionários do IAG. 


\section{Resumo}

Meireles, Ana Luiza de Castro; Silva, Andre Luiz Carvalhal da. Testes Empíricos da Estratégia Dog of Dow nos Mercados Latino Americanos. Rio de Janeiro, 2012. 38p. Dissertação de Mestrado - Departamento de Administração, Pontifícia Universidade Católica do Rio de Janeiro.

O objetivo do presente trabalho é analisar o desempenho da estratégia de investimento Dogs of Dow (DoD) nos mercados latinos americanos no período de 1995 a 2011 bem como determinar se tal desempenho é discrepante em momentos de crise e crescimento econômico. Foram analisados os seguintes mercados: Argentina, Brasil, Chile, Colômbia, México e Peru. Os resultados demonstram que a estratégia DoD possuiu um desempenho superior ao mercado, antes e após ajustar ao risco, em todos os países à exceção do México no período analisado. Os resultados são significativos do ponto de vista estatístico como econômico. Em geral, o desempenho nos sub-períodos apresentou-se em linha com o desempenho no período todo, indicando que, tanto em momentos de crise como de crescimento, as estratégias DoD tem retorno superior ao mercado.

\section{Palavras-chave}

Dog of Dow; Ação de Valor; Retorno de Dividendo. 


\section{Abstract}

Meireles, Ana Luiza de Castro; Silva, Andre Luiz Carvalhal da (Advisor). Empirical Tests of Dog of Dow Strategy in Latin American Stock Markets. Rio de Janeiro, 2012. 38p. MSc. Dissertation - Departamento de Administração, Pontifícia Universidade Católica do Rio de Janeiro.

The goal of this study is to analyze the performance of the Dogs of Dow (DoD) investment strategy in Latin American stock markets from 1995 to 2011 and also determine if the performance varies on growth and recession periods. The following countries were analyzed: Argentina, Brazil, Chile, Colombia, Mexico and Peru. Our findings suggest that the DoD outperforms the market, on an absolute and on a risk-adjusted basis, in all Latin American countries except Mexico. The results are significant in both statistical and economic terms. In general, the performance of DoD in different sub-periods is in line with the overall period, indicating that the DoD has a superior performance in both growth and recession periods.

\section{Keywords}

Dog of Dow; Value stocks; Dividend Yield 


\section{Sumário}

1. Introdução 9

2. Revisão bibliográfica 11

2.1. A estratégia Dogs of the Dow 11

2.2. Política de dividendos: menor risco 12

2.3. Ação de valor: maior retorno 13

$\begin{array}{ll}\text { 2.4. Resultados da estratégia DoD } & 16\end{array}$

3. Dados e metodologia 21

3.1. Dados 21

$\begin{array}{ll}\text { 3.2. Metodologia } & 21\end{array}$

4. Resultados 23

4.1. Argentina 23

4.2. Brasil 25

4.3. Chile 27

4.4. Colômbia 29

4.5. México 30

4.6. Peru 32

5. Conclusão 35

6. Referências bibliográficas 36 


\section{Lista de tabelas}

Tabela 1 - Desempenho Mensal em Dólar das Estratégias DoD na Argentina 24

Tabela 2 - Desempenho Mensal em Dólar das Estratégias DoD no Brasil 25

Tabela 3 - Desempenho Mensal em Dólar das Estratégias DoD no Chile 28

Tabela 4 - Desempenho Mensal em Dólar das Estratégias DoD na Colômbia 29

Tabela 5 - Desempenho Mensal em Dólar das Estratégias DoD no México 31

Tabela 6 - Desempenho Mensal em Dólar das Estratégias DoD no Peru 33 